\title{
Adjacent temporalities: Making Medico-Scientific Futures and the Present
}

\author{
SAMUEL TAYLOR-ALEXANDER \\ University of Edinburgh
}

\section{Keywords}

adjacent temporalities; coproduction; health policy; face transplantation

\section{The Concept as Response}

This essay offers the concept of "adjacent temporalities" to draw attention (1) to how different sociotechnical spaces and processes have different temporalities; (2) how this influences the relation between episteme and ontos; and (3) to the choreography that is needed to link these temporalities together in order to stabilize emerging technoscientific practices. By choreography I refer to the "process of forging a functional zone of compatibility that maintains referential power between things of different kinds" (Cousins 1996, 600), that is, which brings together the clinical, technical, scientific, legal, and political aspects of technoscientific projects. I offer the concept as a response to my reading of STS studies in ontology, which is coupled to my empirical engagement with the field of face transplantation (Taylor-Alexander 2014a; Taylor-Alexander 2015), especially the changing regulatory status of the face for transplantation. What struck me about the extant body of STS literature on ontology and on "making matter matter" was the profound omission of time and temporality from the conceptual equation. The result is often a reading that sees ontological discordance, where a "thing" is different "here and there" (Mol 2002; Mol 2010) as a result of variations in knowing, as if knowing / being are static activities."

By adjacent temporalities I refer to the multiple ways in which a thing is done in mutually contingent presents-its beginnings and endings, how it starts and stops in meaning, in matter, and in time vis-à-vis the locales of its enactments. The aim is thus to draw attention to the importance of attending to time when producing an account of ontology and matter. In this piece I demonstrate the utility of adjacent temporalities as an analytic concept by using it to think through the changed regulatory status of the face for transplantation. It helps to reveal how both the materiality and meaning of what is the face have been modified by the advent of face transplantation and corollary medical and policy developments. Here, we can see at least four social spaces, each with their own temporalities-the clinic and transplant policy in the present, and the same two spaces in a nascent future-that are in flux

Samuel Taylor-Alexander, Email: samuel.taylor-alexander@ed.ac.uk

2For an overview of this literature see Woolgar and Lezuan (2013).

Copyright (C) 2015 (Samuel Taylor-Alexander). Licensed under the Creative Commons Attribution Non-commercial No Derivatives (by-nc-nd). Available at estsjournal.org. 
and being forged in the contemporary. There is a feedback loop between the future and the present, and an epistemic architecture facilitates the choreography that links these four temporal spaces together. Each of these spaces has its own, sometimes murky, ontologies: while in the clinic the face is only ever temporarily an organ, its regulatory status as an organ is constant, if amenable to future change.

Below I provide a brief overview of how the face became an organ in United States transplant policy and thus in the performance of face transplant surgery. I reflect on the changing status of the face as an instance of coproduction, ${ }^{,}$of the ongoing, interlinked making of epistemic and political order in experimental biomedicine (Jasanoff 2004; Taylor-Alexander 2014a): While it is nothing new to write about such issues, utilizing the concept draws attention to how the enactment of multiple temporalities is altering and underlies attempts to secure sociotechnical stability and the temporal choreography that in linking corollary ways of doing/ knowing ties them to a nascent future.

\section{The Example}

Late last year, the first face transplant in the US was performed since changes to the regulation of the field came into effect in July 2014. Following these changes, the face for transplantation is classified as a Vascularized Composite Allograft (VCA) Organ, and is regulated by the same Federal institutions, and health policy, as other forms of organ transplantation. The changes to national transplant law and the redefinition of an organ to include VCAs mean that the face for transplantation now has a rather peculiar ontological status in the present. It is never just a face and never fully an organ; it is only an organ once it is removed from the donor and transplanted to the recipient, at which point it straightaway becomes a face. Reporting on the above mentioned operation, David McCormack (2014) of The Daily Mail described the procedure as follows: "Doctors transplanted about two-thirds of the scalp, the forehead, upper and lower eyelids, eye sockets, nose, upper cheeks, upper jaw, upper teeth, salivary glands and nerves, muscles and skin." Significant in the abovementioned operation is not only the new ways in which the face is medicalized and politicized; the very meaning, boundaries, contours and limits of the face are changing in the process. What the face is, exactly, and how it should be governed as a medicinal therapeutic object, are both at stake in this biomedical realm.

Face transplantation is a form of reconstructive surgery. It is utilized for repairing trauma to the face caused by events such as gunshots, burns, and animal attacks. Since it was first discussed, it has been the subject of intense ethical scrutiny, as it requires submitting persons with non-biologically life threatening conditions to a potentially fatal medical procedure and equally dangerous, life long course of immunosuppressant drugs.

In mid-2008, just months before she performed the first face transplant operation in the US (and three years after the first procedure was performed in France) reconstructive surgeon Maria Siemionow published an article in Annals of Plastic Surgery entitled "Face as an organ" (Siemionow \& Somnez 2008). In the piece the surgeon compares the anatomy of the

${ }^{3}$ The case serves as an example of (a) interactional coproduction, in that it points to the feedback loop between policy and experimental biomedicine, and (b) constitutional coproduction in that the very materiality of the face for transplantation is/ was at play. 
human face to that of the human kidneys, and couples her analysis to numerous studies of the role of the face in vital human biological processes, such as the regulation of blood pressure. Dr. Siemionow's now completed quest is one of a number of developments that are changing "how the face is done" in the present and in the near future. It was the liminal position of the face for transplantation and the murkiness surrounding its regulatory status that contributed to the emergence of the VCA organ as a new regulatory object in US Federal Health Policy (Taylor-Alexander 2014b).

A key motivation for placing face transplantation under the jurisdiction of national transplant bodies was, according to the Department of Health (2013), to "increase safety.... and provide equitable and consistent national access" to VCA organs by "facilitating the collection of data for studying outcomes and best practices, maximizing the benefit to patients and society ... [while] conveying to the public that donation for such purpose will serve an essential medical need." This regulatory shift has resulted in the implementation of a nationwide, standardized database for documenting and measuring outcomes that in harmonizing face transplant protocols aims to bolster both epistemic and political legibility. An increasing number of studies have shown that "the promulgation and enforcement of standards is a central type of social regulation" (Timmermans and Epstein 2010). Here, standardization allows for the mobilization and centralization of a legible body of data, for a choreography that ties together the different temporal enactments of doing the face.

Deeming the face an organ, and thus altering its epistemic and political status, has been a central tactic in attempts to secure the future of face transplantation. In his influential history of synthetic biology, Hans-Jörg Rhienberger (1997) dubbed "machines for making the future" those experimental systems that work by producing knowledge in the present while simultaneously generating future avenues of scientific inquiry. Taking inspiration from this example, I view the shift in the regulatory status of the face from tissue to organ as a method for generating knowledge in the present to secure a biomedical future in which face transplantation is rendered safe and necessary. In contrast to generating future avenues for inquiry, the data collected by the agency that now regulates the field, the Organ Procurement and Transplant Network, will be used to augment policy guidelines.

This mode of future making entails a harmonization of ways of knowing / doing the face, which is central to the choreography that I have referred to above. The piece of law that governs organ transplantation in the US is referred to in short as the "OPTN Final Rule." The modifications to this law were made in late 2013 and required the national transplant agency to develop policies for VCA transplant before July 3, 2014. Following amendments to the Final Rule, now "Organ means a human kidney, liver, heart, lung, pancreas, intestine (including the esophagus, stomach, small and/or large intestine, or any portion of the gastrointestinal tract) or vascularized composite allograft." Accompanying the classification of VCAs as an organ are nine criteria. For a graft to be considered a VCA, it must be something:

(1) That is vascularized and requires blood flow ... (2) Containing multiple tissue types; (3) Recovered from a human donor [and] (4) Transplanted into a human recipient as an anatomical/structural unit; (5) Minimally manipulated ... (6) For

" The liminal position I refer to here is the threshold between organ and tissue. 
homologous use ... (7) Not combined with another article such as a device; (8) Susceptible to ischemia ... and [to] (9) allograft rejection, generally requiring immunosuppression ...(Department of Health and Human Services 2013)

Here I find useful Annemarie Mol's (2002) praxiological approach to biomedicine in which doing and knowing the body are inseparable, and Karen Barad's (2007) emphasis that knowing and doing also influence being, that is, the very materiality of the object of scientific engagement. The changes to national transplant law and the redefinition of an organ to include VCAs mean that the face for transplantation now has a rather peculiar ontological status in the present. It is never just a face and never fully an organ; it is only an organ once it is removed from the donor and transplanted to the recipient, at which point it straightaway becomes a face.

Unlike solid organs-kidneys, hearts and livers-the face is not considered an organ until it is harvested and transplanted for therapeutic purposes. There are a number of clinical practices that are necessary for this to take place: how the face is enacted, how its materiality changes in the performance of face transplants is mediated by its new classificatory status. Alongside new procedures for informed consent and allocation, how the face is treated in the clinical space has also been standardized. It must be labelled in a new way, travel accompanied by paperwork, not be combined with "another article or device," and used solely for replacing a person's body part. (If the procedure does not conform to the last two criteria, the face becomes tissue and the operation falls under the regulatory authority of the FDA, which hypothetically means the graft could be sold.) What the face is, how it is understood and constituted in the clinical arena, has thus been altered through the implementation of new regulatory policy.

As a vascularized composite allograft the face extends past the immediate area of the face to include extra soft and hard tissue-veins, nerves, bone, scalp, muscle, cartilage, etcetera-to aid operative outcomes. Following Mol's (2002) account of how medicine enacts its objects, we may say that the ontological status of the face in this form of medicine is thus both fluid and fractured: what is the face, its materiality, is open change vis-à-vis its new political status and the necessities of clinical practice. Moreover, this new way of doing the face emerged through the ongoing coproduction of epistemic and political order and attempts to secure the future of face transplantation. There is a seeming tension at play here. This arises due to different social spaces having their own temporalities. While the face is enacted as an organ only momentarily in the clinical space, as a transplantable part of the human body it endures (now) constantly as an organ in the realm of policy. And, in both of these spaces, the face is done as an organ in order to secure, and reorder, the future of the field.

This tension is both a result of and central to the choreographic work underway in this new field of organ transplantation. The current policy language surrounding VCA transplantation is only temporary, as is the definition of a VCA organ itself: once initial data collection has taken place, the authorities overseeing the procedure plan to submit outcomes for public comment. Changes to the definition of a VCA, and thus what counts as a face in this realm of biomedicine, could be made in the future depending on factors ranging from public concerns to the success of current transplant protocols and the development of new biomedical technologies. As mentioned above, the expansion of US transplantation policy to 
include face and other VCA organ transplantation aims to "facilitate the collection of data for studying outcomes and best practices" by standardizing clinical practice and record keeping.

\section{In Conclusion}

I have spoken to three interrelated observations that are drawn together by the notion of adjacent temporalities: The first is that different sociotechnical spaces have different temporalities, and I demonstrated this point by exploring the contrast between and coproduction of biomedical time and bureaucratic time. In the former, the face is an organ only sporadically and momentarily while in policy it endures indefinitely. The second coupled observation is that questions of sociotechnical times-spaces play an important role in the doing and knowing of matter. Prior to the discussed legal changes, there was no unified procedure for recording or assessing the different transplant methods used in the field. Assessment of the field and the implementation of best practice guidelines and other governance mechanisms will be an iterative process that involves examination of clinical outcomes. This examination has been made possible inter alia by the standardization of what is the face for transplantation, its materiality in the operating theatre, which is tied to and provides the basis for producing knowledge. This knowledge will then be used to make decisions about the future of the field, to inform policy that (like the discussed legal change) could further alter what counts as a face for transplantation. The third point is that a form of choreography is needed to link together the adjacent time-spaces of the contemporary and to tie these to the nascent future. In my example, this is happening through a form of coordination that allows for the production of metrics and that brings together the clinical, technical, scientific, legal, and political aspects of face transplantation.

Examining the multiple ways that a thing is done in contingent presents reveals the role of time and temporality in the transformation and stabilization of that thing in the locales of its enactment. While in this paper that "thing" is the face for transplantation, it might be a disease in clinical medicine that mutates in the time between its various genetic, imaging, and symptomatic diagnosis causing a tension that ultimately shapes the treatment pathway. ${ }^{.}$The concept of adjacent temporalities is an intervention into current inquiries and approaches to ontology in Science and Technology Studies that emphasize enactment and context but not how the doing of science and medicine (and matter more generally) are shaped in, through, and by time.

\section{Acknowledgements}

I wish to thank Gerard Porter and the anonymous reviewers at Engaging Science, Technology and Society for their useful commentaries on this paper. Daniel Lee Kleinman and Katie Vann have provided invaluable editorial support. My current research is funded by the Wellcome Trust Award No: WT103360MA.

\footnotetext{
${ }^{5}$ Here I offer a potential re-reading of the diagnostic tensions discussed by Mol (2002), who examines the discordance resulting from variation in ways of doing / knowing illness in biomedicine. Attending to adjacent temporalities requires asking, for example: Can such tensions result from changes in the materiality of an illness in the time between respective diagnostic tests?
} 


\section{References}

Barad, K. 2007. Meeting the Universe Halfway: Quantum Physics and the Entanglement of Matter and Meaning. Durham, NC: Duke University Press.

Cussins, C. 1996. Ontological choreography: Agency through objectification in infertility clinics. Social Studies of Science, 26(3), 575-610.

Department of Health and Human Services. 2013. Federal Register Volume 78, Number 128. http:// www.gpo.gov/fdsys/pkg/FR-2013-07-03/html/2013-15731.htm

Jasanoff, S. 2004. States of Knowledge: The Coproduction of Science and Social Order. New York: Routledge

McCormack, D. 2014. "Second face transplant successfully carried out at Cleveland hospital that pioneered." The Daily Mail. Accessed March 25, 2015,

http:/ / www.dailymail.co.uk/news/article-2839470/Cleveland-Clinic-does-2nd-facetransplant.html - ixzz3KGLYajz60

Mol, A. 2002. The Body Multiple: Ontology in Medical Practice. Durham, NC: Duke University Press.

Mol, A. 2010. "Actor-Network Theory: Sensitive terms and enduring tensions." Kölner Zeitschrift für Soziologie und Sozialpsychologie 50(1): 253-269 Rheinberger, Hans-Jörg. 1997. Toward a History of Epistemic Things: Synthesizing Proteins in the Test Tube. Stanford: Stanford University Press.

Siemionow, M. and E. Sonmez. 2008. "Face as an Organ." Annals of Plastic Surgery 61(3): 345352.

Taylor-Alexander, S. 2014a. On Face Transplantation: Life and Ethics in Experimental Biomedicine. Basingstoke: Palgrave Macmillan

Taylor-Alexander, S. 2014b. "How the face became an organ." Accessed August 11, 2014. http:/ / www.somatosphere.net/2014/08/how-the-face-became-an-organ.html

Taylor-Alexander, S. 2015. "Liminality, possibility, and imperative: Performing the other in face transplantation." Medicine Anthropology Theory, 2(1): 165-171

Timmermans, S. and S. Epstein. 2010. "A World of Standards But Not a Standard World: Toward a Sociology of Standards and Standardization." Annual Review of Sociology 36: 69-89.

Woolgar, S. and J. Lezaun. 2013. “The Wrong Bin Bag: A Turn to Ontology in Science and Technology Studies?" Social Studies of Science, 43(3), 321-340. 